Research article

\title{
Genetic diversity of Safflower (Carthamus tinctorius L.) genotypes at Wollo, Ethiopia using agro-morphological traits
}

\author{
Anwar Kemal ${ }^{1,2} *$ and Faris Hailu ${ }^{2}$ \\ ${ }^{1}$ Department of Biology, College of Natural and Computational Science, Mizan-Tepi University, \\ P.O. Box: 121, Tepi, Ethiopia \\ ${ }^{2}$ Department of Biology, College of Natural and Computational Science, Wollo University, \\ P.O. Box: 1145, Dessie, Ethiopia
}

*Corresponding Author: ak.anwarkemal@gmail.com

[Accepted: 22 April 2019]

\begin{abstract}
Safflower (Carthamus tinctorius) is an annual oilseed crop of the Compositae or Asteraceae family commercially grown in Ethiopia and other countries. To study the genetic variation and relationships among twelve Safflower genotypes an experiment was carried out under field conditions in randomized complete block design with 3 replications in Wollo University, Dessie campus using the agro-morphological traits that includes plant height, days to flowering, Days to maturity, number of primary branches, number of secondary branches, number of capitula per plant, number of seed per capitulum, thousand seed weight, yield per plant, and yield per plot. Results of the analysis of variance showed significant differences among accessions for traits like days to flowering, days to maturity at $\mathrm{p} \leq 0.01$, and for number of primary branches and number of secondary branches at $\mathrm{p} \leq 0.05$. Seed yield per plant had significant correlations with number of capitula per plant, number of seeds per capitulum, number of primary and secondary branches. Cluster analysis grouped the 12 genotypes in 2 clusters and one of the accessions remains ungrouped, according to their similarity in various traits studied. The first three principal component analyses were found to explain $85 \%$ of the total variation that exists among accessions. The results revealed the presence of a high level of genetic diversity that deserves conservation attention and could be utilized in breeding program to improve Safflower varieties with a high seed yield.
\end{abstract}

Keywords: Cluster analysis - Genetic variation - Genotype - Morphological character - Safflower.

[Cite as: Kemal A \& Hailu F (2019) Genetic diversity of Safflower (Carthamus tinctorius L.) genotypes at Wollo, Ethiopia using agro-morphological traits. Tropical Plant Research 6(1): 157-165]

\section{INTRODUCTION}

Safflower (Carthamus tinctorius L.) is an annual oilseed crop of the Compositae or Asteraceae family commercially grown in Australia, Ethiopia, India, Mexico, United States, and several other countries (Hashemi et al. 1994). Many countries grow Safflower around the world including Ethiopia. India and Ethiopia are the countries with the longest tradition of growing Safflower as an oil plant (Weiss 2000). Vavilov (1951) proposed Ethiopia, Afghanistan and India as centers of origin of cultivated Safflower. Safflower is one of the important underutilized oilseed crops cultivated in a wide range of ecological environments, but it is generally regarded as a crop for semi-arid regions (Johnson \& Marter 1993). It is adaptable to conditions in wide ranging climate zones from $60^{\circ} \mathrm{N}$ to $45^{\circ} \mathrm{S}$ it should therefore be suitable for cultivation in regions with a temperate climate (Esendal 2001). Safflower production under excessive moisture and high humidity conditions is seriously susceptible to diseases (Mündel et al. 2004). The crop has multipurpose crop of economic importance in a few countries around the world (Knowles \& Ashri 1995), and Ethiopia is one of the major producers of Safflower in the world.

Traditionally, Safflower has been grown for centuries from China to the Mediterranean region and all along the Nile valley up to Ethiopia (Weiss 1971). Safflower has been used in the Middle East, India and Africa for purgative and alexipharmic (antidote) effects, as well as in a medicated oil, to promote sweating and cure fevers 
(Weiss 1971). In different parts of the world carpet-waving industries were used Safflower dies. Carthamin dye was used widely to color cloth until the 19th century, when cheaper aniline dyes became available (Weiss 1983). Traditionally, the crop was grown f.or its yellow-orange flowers, used for coloring and flavoring foods, and making dyes (Knowles 1989).

In spite of the large volume of vegetable oils traded around the world, $75 \%$ of the production is from only four crops: soybean, oil palm, rapeseed and sunflower (Khan et al. 2008). These four crops dominated over the other crops (Murphy 1999) and many other oil crops are now underutilized or neglected, despite the fact that these species provide opportunities through their great genetic diversity and diverse agro-ecological adaptation (Thies 2000). Considering the increasing market demand for high polyunsaturated food products in developed countries Safflower is an oilseed crop with great potential. In addition, there are signs of recent growth in the market for Safflower, the price premium for Safflower oil and optimistic prospects have motivated a number of countries to introduce Safflower as an oilseed crop (Johnson \& Marter 1993). Safflower oil is thought to be one of the highest quality vegetable oils, containing oleic acid and linoleic acid (Khan et al. 2008). As a rainfed crop, Safflower is adapted to some regions and sown by growers when environmental and economic conditions are suitable (Wachsmann et al. 2008).

Currently, Safflower is regarded as an important oilseed crop, and is grown commercially for its edible oil rich in polyunsaturated fatty acids (Dwivedi et al. 2005, Singh et al. 2007). It is usually grown after cereals or fallow in crop rotation and can be adapted in organic production systems (Bavec \& Bavec 2007). Safflower is rich in vitamin A, iron, phosphorus, and calcium. Young raw plants of Safflower are sold in markets in countries such as India and other countries (Nimbkar 2002). Safflower has become an industrial crop production platform based on low out-crossing and weediness habits, a different appearance from other oilseed crops such as canola and excellent agronomic traits such as taproot architecture that accesses sub-soil water reserves (Markley et al. 2006).

The research and development on different aspects of Safflower, despite its adaptability to varied growing conditions with very high yield potential and diversified uses of different plant parts, have not received due attention. This probably is the main reason for its status as a minor crop around the world in terms of area and production, compared to the other oilseed crops. However, interest in this crop has been rekindled in the last few years due to three major reasons (Singh et al. 2007): (1) A huge shortfall in oilseed production in countries having a sizable area with scanty rainfall, to which Safflower is most suited; (2) The preference of consumers for healthy oil with less amounts of saturated fats, for which Safflower is well known; (3) The medicinal uses of flowers in China and extraction of edible dyes from flowers have become more widely known.

The success of Safflower as a commercial oil seed crop in traditional areas and its expansion in new areas will mainly depend on the level of improvement made in both its yield and oil content. The low oil content of 28-30 percent and low yield of $600 \mathrm{~kg} \mathrm{ha}^{-1}$ makes Safflower a poor competitor. Safflower developed considerable diversity after it was taken into cultivation for a long time across huge and diverse regions in the Old World, and there is evidence of incipient genetic differentiation (Knowles 1989). Introduction is the simplest way to facilitate crop improvement and has been used successfully to establish many oilseed crops in new areas (Knowles 1983). Further domestication and development of underutilized crops is a possible solution for the growing and diversified nutritional needs of humankind (Muhammad et al. 2001).

Safflower has received limited research resulting in only small improvements in production, a limited range of cultivars and deficiencies in the awareness of adaptation and agronomic requirements (Wachsmann et al. 2008). Moreover, limited attention has been given to conserve, add value and improve the productivity of Safflower in Ethiopia (Edwards 1991).

Ethiopian Safflower is neglected and underutilized so far, it is cultivated only as a minor oil crop with inadequate information available on its genetic resources. In Ethiopia, Safflower cultivation is mostly done by small farmers in well fertile and drained field, usually around homesteads. However, seeds harvested from the plant are used for oil extraction, roasted seed and other traditional uses (seed is extracted into drinks used during fast by people in Wollo region). But industrial applications of Safflower plants remain as low acreage crop compared to other oilseed crops like sesame. This demonstrates a need for research examining the agronomic performances of newly released Safflower genotypes in diverse environments (Öztürk et al. 2008).

Understanding the extent and distribution of genetic diversity within species help in the future breeding program of Safflower (Padulosi et al. 1999). The diversity of Safflower in Wollo region could mainly be attributed to different agro ecological conditions. The comparison of various agronomic characters of genotypes 
under agro climatic condition of Safflower growing areas in Wollo region helps agronomists and the local

farmers in the crop improvement.

The main objective of the study was to investigate the genetic diversity among the genotypes of Safflower in Wollo, Ethiopia. The specific objectives were to assess the genetic variation of $C$. tinctorius genotypes using agro-morphological traits and to identify high yielding, better adapted genotypes of Safflower for future use in improving the crop.

\section{MATERIALS AND METHODS}

Description of the study area

Wollo is located in the Amhara Regional State and the experiment was carried out in the field at Wollo University, Dessie ( $11^{\circ} 8^{\prime} \mathrm{N}$; $39^{\circ} 38^{\prime} \mathrm{E}$; with an annual rainfall of $900-1400 \mathrm{~mm}$ ). Dessie is located at about 401 $\mathrm{km}$ of Addis Ababa to the north. Wollo province comprises diverse agro-climatic condition with different altitudinal ranges. Most of the region is characterized by mountainous, semi-arid environmental condition. The accessions were collected from different major Safflower producing sites representing different landraces in the region.

\section{Plant material}

Safflower (Carthamus tinctorius L.) is herbaceous, branched and thistle-like annual plant with strong taproots which help them to survive in dry climates. Safflower is a highly branched, herbaceous, thistle-like annual or winter annual, usually with many long sharp spines on the leaves. Plants are $30-150 \mathrm{~cm}$ tall with many spines on the leaves, globular flower heads (capitula) and commonly, brilliant yellow, orange or red flowers (Fig. 1). Achenes are smooth, four-sided and generally lack pappus (Le \& Mündel 1996).
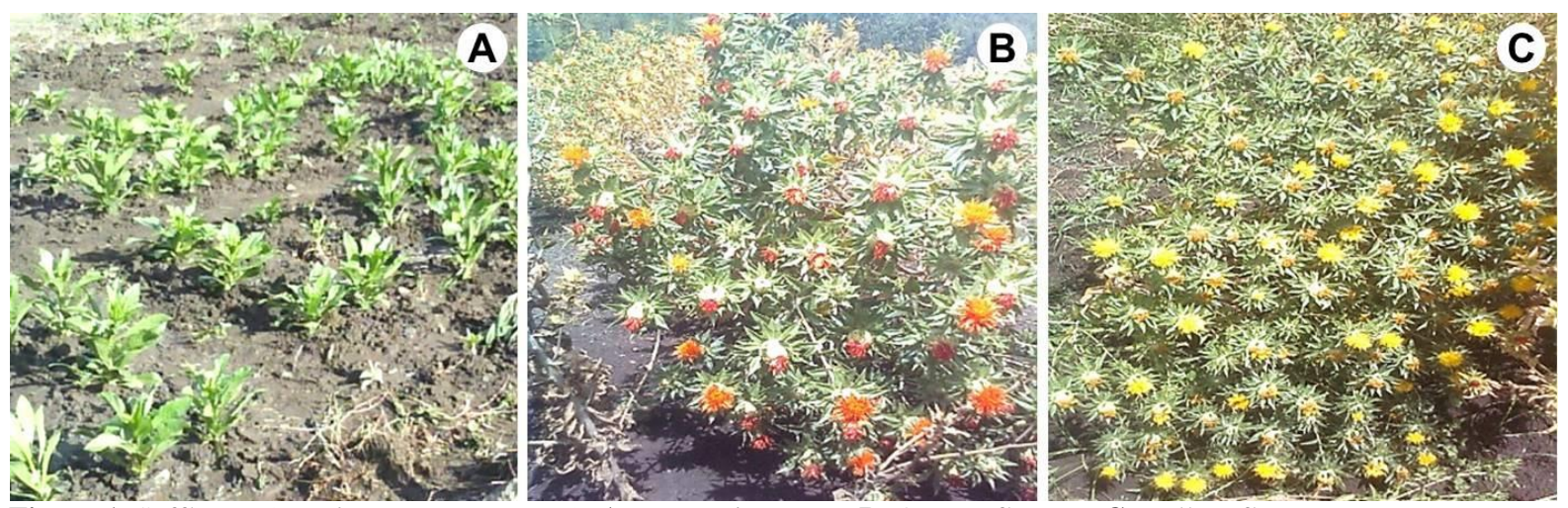

Figure 1. Safflower (Carthamus tinctorius L.): A, Vegetative stage; B, Orange flowers; C, Yellow flowers.

A total of twelve Safflower accessions collected from different parts of Wollo region were planted in the experimental field at Wollo University, Dessie. For the 12 accessions seven of the seed samples were received from EBI (Ethiopian Biodiversity Institute) and the remaining five were collected by the researcher (Table 1). The accessions were planted in January 2014 and harvested in the early July 2014 manually at maturity before the beginning of the main rain season. Several agro-morphological characters were recorded during the field experiment.

Table 1. List of Safflower accessions and regions of collection used in this study.

\begin{tabular}{llrrr}
\hline No. & Accession No./ Name & Region & Zone & Woreda \\
\hline 1 & 51526 & Amhara & South Wollo & Tenta \\
2 & 207477 & Amhara & South Wollo & Ambasel \\
3 & 212588 & Amhara & South Wollo & Ambasel,1440m \\
4 & 214915 & Amhara & North Wollo & Wadla \\
5 & 241792 & Amhara & North Wollo & Meket, 2045m \\
6 & 241793 & Amhara & North Wollo & Bugna, 2070m \\
7 & 241794 & Amhara & North Wollo & Bugna, 1990m \\
8 & Kundi & Amhara & South Wollo & Kutaber \\
9 & Barkana & Amhara & South Wollo & Kutaber \\
10 & Kalu & Amhara & South Wollo & Kalu \\
11 & Argoba & Amhara & South Wollo & Argoba \\
12 & Kola Gerado & Amhara & South Wollo & Kutaber \\
\hline
\end{tabular}

Field experimental procedures

www.tropicalplantresearch.com 
The field experiment was laid out using Randomized Complete Block Design (RCBD) with three replications to plant the 12 accessions systematically and field heterogeneity was controlled. Each accession was represented by a single $1.6 \mathrm{~m} \times 1.6 \mathrm{~m}$ plot per replication with $0.5 \mathrm{~m}$ gap between plots. The spacing between rows of each plot was $40 \mathrm{~cm}$ and spacing between plants was $20 \mathrm{~cm}$. To study the quantitative data five individual plants was tagged within each plot randomly for later morphological variation evaluation. Manual thinning was used after emergence to obtain normal density. Fertilizers were applied at $100 \mathrm{~kg} \mathrm{~N} \mathrm{ha}^{-1}$ and 100 $\mathrm{kg} \mathrm{P} \mathrm{ha}{ }^{-1}$ prior to sowing and $50 \mathrm{~kg} \mathrm{~N} \mathrm{ha}^{-1}$ after sowing and at shooting stage. The crop was irrigated as needed. All accessions were provided with the same agronomical practices and weeds were manually controlled.

\section{Data collection}

Agro-morphological characters as described below were recorded from five randomly chosen plants per plot.

A. Plant height $(\mathrm{PH})$ : The main stem length in centimeter $(\mathrm{cm})$ from ground level to the tip of mains stem at maturity time

B. Days to flowering (DF): Total number of days taken from the date of sowing to the day of first flower opening in each plant

C. Days to maturity (DM): Total number of days taken from the date of sowing to the day of the complete maturation of the plant

D. Number of Primary branches (NPB): Total number of primary branches produced on the main stem by individual plant

E. Number of secondary branches (NSB): Total number of secondary branches arising from the primary branches in each randomly selected plant

F. Number of capitula per plant (NCP): Total number of capitula produced by a single plant at maturity stage

G. Number of seeds per capitulum (NSC): Total number of seeds obtained from main capitulum

H. Thousand seed weight (TSW) (g): The weight of one thousand seeds from randomly selected seeds were weighed

I. Yield per plant (YPP) (g): The individual plant was threshed and the yield of a single plant was measured

J. Yield per plot (YPPt) (kg): The total seed yield obtained from each plot was measured and recorded

Data analysis

The genetic diversity and relationships among Safflower genotypes were evaluated using quantitative data analysis. All traits recorded in the data collection were statistically analyzed by applying SPSS version 20 . Morphological traits of each genotype were measured on five randomly chosen plants in each replication for genetic diversity analysis of Safflower accessions from Wollo region.

i. Analysis of variance: Analysis of variance of data for agro-morphological characters was performed using SPSS statistical package. The quantitative data for all the parameters were subjected to analysis using SPSS statistical computer package version 20. Range, mean, standard deviation and variance were calculated for each trait.

Data taken from five sample plants in each plot (from middle rows) was used in the analyses for traits that required sampling. Total variation was partitioned in to known and unknown effects following the standard procedures of ANOVA given in table 2 (Gomez \& Gomez 1984).

Table 2. Source of variation, degree of freedom and mean squares for RCBD.

\begin{tabular}{lrrr}
\hline Source of variation & Degree of freedom & Mean square & Expected mean square \\
\hline Replications & $(\mathrm{r}-1)$ & $\mathrm{MS}$ & $\sigma_{\mathrm{r}}^{2} \mathrm{e}_{\mathrm{e}} \sigma_{\mathrm{r}}^{2}$ \\
Genotypes & $(\mathrm{g}-1)$ & $\mathrm{MS}_{\mathrm{g}}$ & $\sigma_{\mathrm{e}}^{+} \sigma_{\mathrm{g}}^{2}$ \\
Error & $(\mathrm{r}-1)(\mathrm{g}-1)$ & $\mathrm{MS}_{\mathrm{e}}$ & $\sigma_{\mathrm{e}}^{2}$ \\
\hline
\end{tabular}

Note: $r$ - Number of replications, g- Number of genotypes, $\mathrm{MS}_{\mathrm{e}^{-}}$Mean square of error, $\mathrm{MS}_{\mathrm{r}^{-}}$Mean square of replication, $\mathrm{MS}_{\mathrm{g}}$ - Mean square of genotypes.

ii. Correlation coefficient (r): The associations among various agro-morphological traits were estimated using simple Pearson's product moment correlation coefficients by using SPSS statistical package software of version 20, with appropriate degrees of freedom and probability level, significance of the correlation coefficients was tested.

iii. Cluster Analysis: Cluster analysis was carried out to identify the traits that account for the genetic variation and to determine pattern of genetic similarity of all accessions. The means of each geographical group for all agro-morphological traits were used for cluster analysis to study the relationship between geographical 
groups. Genetic distance and cluster analysis of agro-morphological data was used to reveal genetic difference within the population of Safflower. The cluster analysis was conducted on average taxonomic distance and a dendrogram was generated based on the genetic distance matrix using SPSS statistical computer package version 20 (Samarajeewa et al. 2004, Seetharam et al. 2004).

iv. Principal Component Analysis: To understand which trait is responsible for the variation that existed among the twelve accessions collected from different region of Wollo, all of the traits were grouped in to different principal components. According to Johnson \& Wichern (2002) it is possible to decide the importance of traits in different principal components. Traits that accounted for the highest variation within each principal component are also described.

\section{RESULTS}

Variance components, mean comparisons, range and standard deviation for plant height, days to flowering, number of primary branches, number of secondary branches, days to maturity, number of capitula per plant, number of seeds per capitulum, thousand seed weight, yield per plant, and yield per plot are presented in table 3 .

\section{Analysis of Variance}

Table 3. Range, mean, standard deviation and variance of accessions used for the study based on agro-morphological traits.

\begin{tabular}{lrrrrrrrrrr}
\hline & PH & DF & NPB & NSB & DM & NCP & NSC & TSW & YPP & YPPt \\
\hline Std. Dev. & 11.241 & 1.437 & 3.373 & 0.921 & 1.521 & 39.227 & 6.420 & 3.201 & 78.124 & 1.861 \\
Mean & 113.917 & 126.361 & 25.400 & 6.383 & 165.028 & 151.650 & 38.811 & 44.483 & 251.406 & 5.902 \\
Range & 48.600 & 6.000 & 13.400 & 3.900 & 6.000 & 137.700 & 24.200 & 13.300 & 289.630 & 6.750 \\
Variance & 126.357 & 2.066 & 11.377 & 0.848 & 2.313 & 1538.763 & 41.220 & 10.248 & 6103.361 & 3.463 \\
\hline
\end{tabular}

Note: PH- Plant height (cm), DF- Days to flowering, DFF- Days to 50\% flowering, DM- Days to maturity, NPB- Number of primary branches per plant, NSB- Number of secondary branches per plant, NCP- Number of capitula per plant, NSDNumber of seed per capitulum, TSW- 1000- seed weight (g), YYP- Yield per plant (g), YYPt- Yield per plot (kg).

The analysis of variance showed significant difference among the accessions in days to flowering, days to $50 \%$ flowering and days to maturity at $\mathrm{P} \leq 0.001$, and number of primary branches and number of secondary branches at $\mathrm{P} \leq 0.05$ shown in table 4 .

Table 4. Mean squares value for eleven agro-morphological trait of Safflower accession.

\begin{tabular}{lrrrr}
\hline Characters & $\begin{array}{r}\text { Replication } \\
(\boldsymbol{d} \boldsymbol{f}=\mathbf{2})\end{array}$ & $\begin{array}{r}\text { Accession } \\
(\boldsymbol{d} \boldsymbol{f}=\mathbf{1 1})\end{array}$ & $\begin{array}{r}\text { Error } \\
(\boldsymbol{d} \boldsymbol{f}=\mathbf{2 2})\end{array}$ & $\mathbf{C . V .}$ \\
\hline Plant Height & 123.86 & 143.64 & 117.94 & 9.87 \\
Days to flowering & 0.1944 & $5.4217^{* *}$ & 0.5581 & 1.14 \\
Number of primary branches & 25.4908 & $17.0382^{*}$ & 7.2636 & 13.28 \\
Number of secondary branches & 0.54333 & $1.44202^{*}$ & 0.72052 & 14.43 \\
Days to maturity & 0.1944 & $6.5126^{* *}$ & 0.4066 & 0.92 \\
Number of capitula per plant & 1033.0 & 2080.9 & 1313.7 & 25.87 \\
Number of seed per capitulum & 40.778 & 31.551 & 46.095 & 16.54 \\
1000 seed weight & 25.4800 & 8.7761 & 9.5988 & 7.20 \\
Yield per plant & 5504.2 & 8712.0 & 4853.5 & 31.07 \\
Yield per plot & 3.4630 & 4.7112 & 2.8392 & 31.53 \\
\hline
\end{tabular}

Note: $d f$ - Degrees of freedom, **- Significant at $\mathrm{P} \leq 0.01$, *- Significant at $\mathrm{P} \leq 0.05$.

\section{Correlation coefficient}

Correlations of yield per plot with other traits shows that yield per plot is significantly correlated, positively with number of capitula per plant (0.87), number of seed per capitula (0.477), plant height $(0.772)$, number of primary branches (0.799), number of secondary branches (0.695) and yield per plant (0.993) and negatively with days to flowering (-0.432). Number of capitula per plant shows significant association with number of primary branches (0.824) and number of secondary branches (0.825). Plant height was positively and significantly ( $p$ $\leq 0.05)$ correlated with number of secondary branches $(0.605)$ and number of seeds per capitulum $(0.308)$, but correlated negatively and significantly $(\mathrm{p} \leq 0.05)$ with days to flowering $(-0.402)$. This may be due to the environmental condition on the field at the experimental site affecting normal flowering of the plant. There is also positive significant association (0.647) between number of primary branches and number of Secondary branches (Table 5).

\section{Cluster Analysis}

As shown in figure 2, 12 Safflower accessions collected from different regions of Wollo were clustered in two groups based on the similarity they reveal and one of the accessions (212588) from Ambasel remain 
ungrouped. The first group consisted of 241793 from Bugna, 51526 from Tenta, Argoba and Barkana. The second group was the largest group and consisted of three accessions from North Wollo (241794 from Bugna, 24792 from Meket, 214915 from Wadla), 207477 from Ambasel, Kundi, Kola gerado and Kalu.

Table 5. Pearson correlation coefficients of Safflower accessions.

\begin{tabular}{|c|c|c|c|c|c|c|c|c|c|c|}
\hline Characters & PH & DF & NPB & NSB & DM & NCP & NSC & TSW & YPP & YPPt \\
\hline $\mathrm{PH}$ & 1 & & & & & & & & & \\
\hline DF & $-.402 *$ & 1 & & & & & & & & \\
\hline NPB & .671 & $-.390 *$ & 1 & & & & & & & \\
\hline NSB & $.605^{*}$ & $-.423 *$ & $.647 * *$ & 1 & & & & & & \\
\hline DM & -.379 & .322 & $-.360 *$ & -.320 & 1 & & & & & \\
\hline $\mathrm{NCP}$ & .757 & $-.518 * *$ & $.824 * *$ & $.825 * *$ & $-.346^{*}$ & 1 & & & & \\
\hline NSC & $.308^{*}$ & -.027 & .348 & .112 & -.280 & .142 & 1 & & & \\
\hline TSW & .300 & -.002 & .071 & .062 & -.068 & .106 & -.045 & 1 & & \\
\hline YPP & .772 & $-.429 * *$ & $.807 * *$ & $.724 * *$ & -.490 & $.876^{* *}$ & $.513 * *$ & .243 & 1 & \\
\hline YPPt & $.772 *$ & $-.432 * *$ & $.799 * *$ & $.695 * *$ & -.476 & $.877 * *$ & $.477 * *$ & .283 & $.993 * *$ & 1 \\
\hline
\end{tabular}

Note: *- Correlation is significant at the 0.05 level (2-tailed), **- Correlation is significant at the 0.01 level (2-tailed). PH- Plant height (cm), DF- Days to flowering, DFF- Days to $50 \%$ flowering, DM- Days to maturity, NPB- Number of primary branches per plant, NSB- Number of secondary branches per plant, NCP- Number of capitula per plant, NSDNumber of seed per capitulum, TSW- 1000- seed weight (g), YYP- Yield per plant (g) and YYPt- Yield per plot (kg).

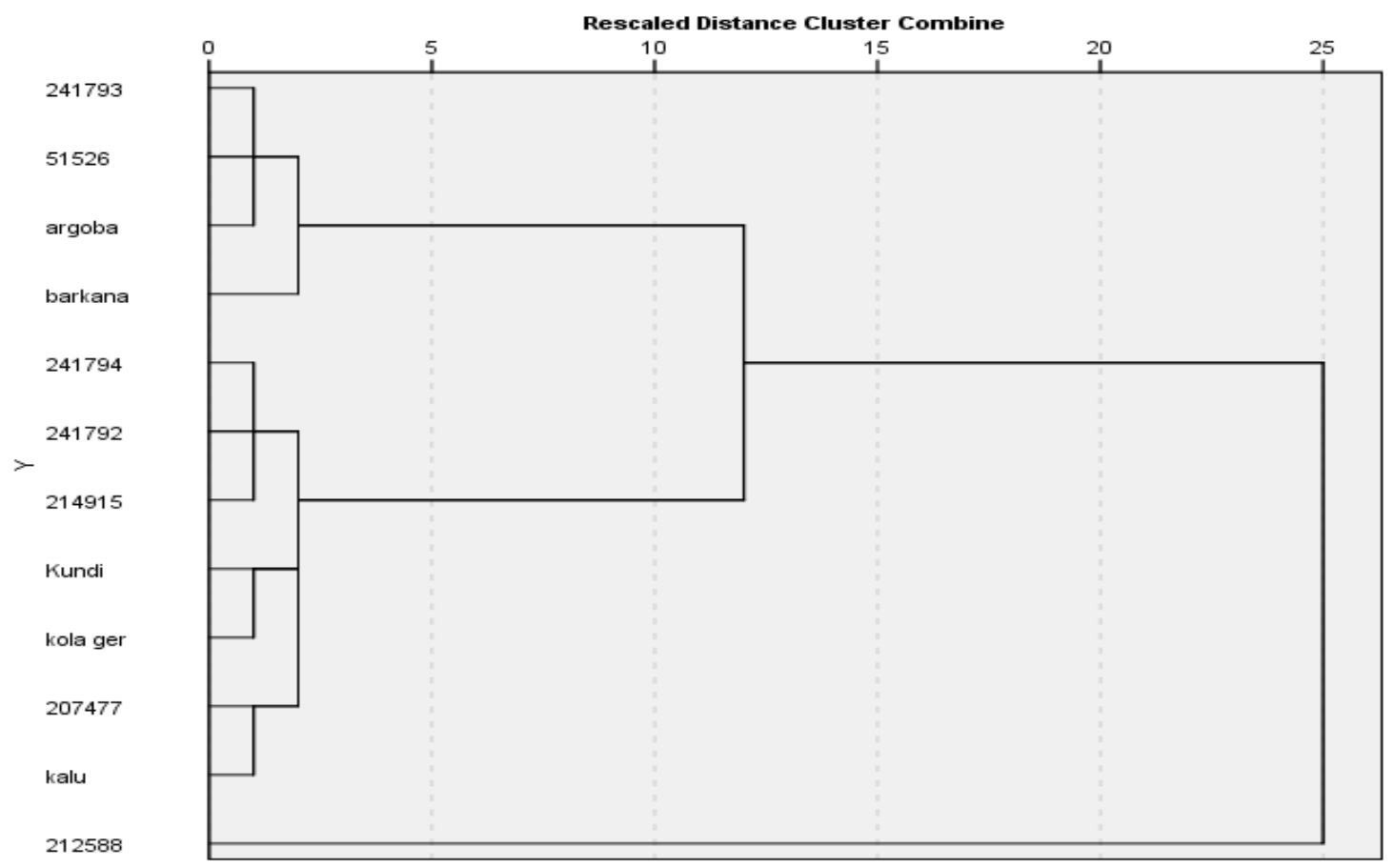

Figure 2. Dendrogram of cluster analysis for 12 Safflower accessions based on morphological traits.

\section{Principal component analysis}

Three principal components, PC1 to PC3 accounted for the $85.8 \%$ of the total variation that exist among accessions. Out of the total principal components retained PC1 and PC2 with values of $60.8 \%$ and $15.9 \%$ respectively contributed more to the total variation. Among the vectors of PC1 which accounted more to the total variation $(60.8 \%)$, yield per plant and yield per plot, number of primary and secondary branches, number of capitula per plant and plant height had higher values. In the second principal component (PC2), which explain about $15.9 \%$ of total variation, originated mainly from days to flowering, number of seeds per capitulum and thousand seed weight. Similarly, among the vectors of PC3, days to flowering, and thousand weight had higher values (Table 6).

\section{DISCUSSION}

Assessing genetic diversity provides helpful information needed in the Performance of a long-term breeding program for crop improvement strategies through selection and hybridization. The use of agro morphological trait can reveal differences among accessions providing efficient tool for crop management and conservation.

In this study, the results showed a considerable genetic variation for different agro-morphological traits among accessions of Safflower as self-pollinating species maintain high genetic diversity at their polymorphic www.tropicalplantresearch.com 
loci (Hamrick \& Godt 1989). From the analysis of variance, traits like days to flowering, and days to maturity showed significant variation at $(\mathrm{p} \leq 0.01)$ and for number of primary branches and number of secondary branches at $(\mathrm{p} \leq 0.05)$ indicating that the accessions collected from Wollo region show considerable genetic variation. Thus, the populations/accessions from the region need to be conserved and managed properly.

Table 6. Eigen values and Eigen vectors of important principal components (PC) for variation among accessions from Wollo region.

\begin{tabular}{|c|c|c|c|}
\hline \multirow{2}{*}{ Characters } & \multicolumn{3}{|c|}{ Eigen vectors } \\
\hline & PC 1 & PC 2 & PC 3 \\
\hline $\mathrm{PH}$ & 0.335780 & 0.102058 & 0.063371 \\
\hline DF & -.257142 & 0.379838 & 0.516803 \\
\hline NPB & 0.361186 & 0.002921 & 0.082258 \\
\hline NSB & 0.332277 & -.190279 & 0.386095 \\
\hline DM & -.219703 & -.264872 & 0.271060 \\
\hline $\mathrm{NCP}$ & 0.368481 & -.102047 & 0.172887 \\
\hline NSC & 0.268732 & 0.319742 & 0.094728 \\
\hline TSW & -.009849 & 0.580866 & -.505288 \\
\hline YPP & 0.375925 & 0.159286 & 0.041671 \\
\hline YPPt & 0.369466 & 0.183532 & 0.000648 \\
\hline Eigen value & 6.68824870 & 1.75395965 & 1.00253491 \\
\hline Proportion & 0.6080 & 0.1595 & 0.0911 \\
\hline Cumulative & 0.6080 & 0.7675 & 0.8586 \\
\hline
\end{tabular}

Significant correlation was recorded between yield per plot and most other traits including yield per plant, number of primary and secondary branches, number of capitula per plant, number of seeds per capitulum, and plant height indicated that the improvements of one trait will lead to yield improvement of Safflower in Wollo region. On the other hand, yield per plot was not significantly correlated with days to maturity and thousand seed weight. Roopa \& Ravikumar (2008) also observed a strong positive correlation between seed yield per plant and number of capitula per plant, number of branches per plant. Thus, improvement of the yield will greatly be efficient via number of primary and secondary branches, number of capitula per plant and number of seeds per capitulum based selection. However, 1000-seed weight was not significantly correlated with any of the other traits. The highest correlation coefficient was obtained between yield per plant and yield per plot (0.993) indicating that the average value of traits measured on five single plants, can be used as a plot representative which is in agreement with (Omidi et al. 2009).

The cluster analysis of Safflower accessions collected from different regions of Wollo showed that the accessions from different regions are located in the same group indicating the absence of distinct regional grouping. This is possibly due to environmental condition that affects performance of Safflower favoring the accessions collected from regions with same environment of the experimental site. This result is in agreement with the result in Ethiopian tetraploid wheat described by Hailu et al. (2006). Thus, accessions could be more effectively clustered when considering traits related to grain yield rather than with geographical origin. Similarly, Omidi et al. (1999) in study of 100 Safflower cultivars also concluded that grouping based on traits related to seed yield per plant is more effective than based on their origin.

As described by Chahal \& Gosal (2002) characters with largest absolute value closer to unity within the first principal component influence the clustering more than those with lower absolute value closer to zero. In this study result from the principal component analysis indicate the presence of variation among different accessions of Safflower in Wollo region identifying that from PC1 which accounted $60.8 \%$ of the total variation yield per plant is the most important trait responsible for highest variation from the component. Thousand seed weight and days to flowering are also important traits that accounted the highest variation from PC2 and PC3 respectively. Thousand seed weight were very important trait responsible for highest variation from all of the three principal components.

In order to achieve effective improvement for seed yield increased number of primary and secondary branches, number of capitula, and number of seeds per capitulum are very important. According to Knowles (1969) the flower colour of cultivated Safflower of Ethiopian origin as red, however, in this study the researcher found that the Safflower accessions collected from different regions showed yellow and orange in addition to red colour (Fig. 1) which vary among and within accessions but white flower colour was not observed in any of the accessions. This shows that in Ethiopia there is a high level of genetic diversity of Safflower that still require more study for better breeding performance and germplasm conservation. 


\section{CONCLUSION AND RECOMMENDATIONS}

The results shown in this study indicates the presence of high genetic variation among twelve accessions collected from Wollo, Ethiopia which is useful for breeding and conservation purposes. Depending upon the results of the data analyzed, appropriate breeding strategies can be adopted for the improvement of target trait. Future breeding strategies to improve Safflower need to exploit the results of this study to increase seed yield potential and other desirable traits.

A lack of information about genetic diversity has been a barrier to improve Safflower in Ethiopia, particularly in Wollo region. The results of this study provided a better understanding of Safflower populations in Wollo region. Therefore, the wise use of results obtained in this study would facilitate the improvement of Safflower through breeding and the in situ and ex situ conservation of Safflower genetic resources in this region. Desirable genotypes in terms of seed yield have been identified in this study and the use of these genotypes in the breeding program would lead to improved Safflower varieties with a high seed yield.

In Ethiopia, Safflower is grown in the field with low agricultural inputs, which resulted in more pests, diseases, and a low seed yield in this crop. Seed yield in Safflower is influenced by different factors such as planting dates, weather patterns, relative humidity, irrigation, fertilizers, and farmers' practices. Cultivation of Safflower under good growing conditions would result in a relatively high seed yield. Therefore, development of high yielding and better adapted genotypes including the cultivation technique need to be improved.

The use of agro morphological traits for assessment of Safflower genetic diversity would help to reveal variation among accession from different regions. Several varieties from agro-morphological evaluation were found to have high seed yield potential, and the use of these varieties would lead to an increased Safflower production in Ethiopia.

\section{ACKNOWLEDGEMENTS}

I am thankful for the continuous encouragement and support of my family in every walk throughout my life. My foremost gratitude goes to Dr. Faris Hailu, for his unreserved help during my study. My appreciation is also extended to Ethiopian Institute of Biodiversity (EBI) for providing the seed samples used in this study.

\section{REFERENCES}

Bavec F \& Bavec M (2007) Organic Production and Use of Alternative Crops. CRC, Taylor \& Francis, Boca Raton, FL.

Chahal G \& Gosal SS (2002) Principles and Procedures of Plant Breeding: Biotechnology and Conventional Approaches. Narosa Publishing House, New Delhi.

Dwivedi SL, Upadhyaya, HD \& Hegde DM (2005) Development of core collection using geographic information and morphological descriptors in Safflower (Carthamus tinctorius L.) germplasm. Genetic Resources and Crop Evolution 52: 821-830.

Edwards K, Johnstone C \& Thompson C (1991) A simple and rapid method for preparation of plant genome DNA for PCR analysis. Nucleic Acids Research 19: 1849.

Esendal E (2001) Global adaptability and future potential of Safflower. Proc of the $\mathrm{V}^{\text {th }}$ Intern Safflower Conf, Williston, North Dakota, Sidney, Montana, USA, pp. xi-xii.

Gomez AK \& Gomez AA (1984) Statistical Procedure for Agricultural Research. John Wiley and Sons, London.

Hailu F, Merker A, Singh H, Belay G \& Johansson E (2006) Multivariate analysis of diversity of tetraploid wheat germplasm from Ethiopia. Genetic Resources and Crop Evolution 53(6): 1089-1098.

Hamrick JL \& Godt M JW (1989) Allozyme diversity in plant species. In: Brown AHD, Clegg MT, Kahler AL $\&$ Weir BS (eds) Plant population genetics, breeding and germplasm source. Sunderland, Sinauer, MA, pp. 43-63.

Hashemi A, Estilai A \& Carapetian J (1994) Variation and Inheritance of Isozymes in Safflower. Journal of the American Society for Horticultural Science 119(3): 624-628.

Johnson A \& Marter A (1993) Safflower products: utilization and markets. Natural Resources Institute, pp. 1213.

Johnson RA \& Wichern DW (2002) Applied Multivariate Statistical Analysis. Prentice-Hall, Upper Sadle River, NJ.

Khan MA, Witzke-Ehbrecht SV, Mass BL \& Becker HC (2008) Relationships among different geographical groups, agro-morphology, fatty acid composition and RAPD marker diversity in Safflower (Carthamus 
tinctorius). Genetic Resources and Crop Evolution 56: 19-30.

Knowles PF \& Ashri A (1995) Safflower Carthamus tinctorius (Compositae). In: Smartt J \& Simmonds NW (eds) Evolution of Crop Plants, ( $2^{\text {nd }}$ edition). Longman Scientific and Technical, pp. 47-50.

Knowles PF (1969) Centers of plant diversity and conservation of crop germplasm: Safflower. The Economic Journal 23: 324-329.

Knowles PF (1983) Genetics and breeding of oilseed crops. The Economic Journal 37: 423-433.

Knowles PF (1989) Safflower. In: Ro "bbelen G, Downey RK \& Ashri A (eds) Oil crops of the world, their breeding and utilization. McGraw Hill, Inc., New York, pp. 363-374.

Li D \& Mündel HH (1996) Safflower Carthamus tinctorius L. Promoting the conservation and use of underutilized and neglected crops, 7. Institute of Plant Genetics and Crop Plant Research, Gatersleben, Germany/International Plant Genetic Resources Institute, Rome, Italy, pp. 83.

Markley N, Nykiforuk C, Boothe J \& Moloney M (2006) Producing proteins using oilbody-oleosin technology. BioPharm International 9: 6-12.

Muhammad A, Noor-ul I \& Khalid MS (2001) Correlation and path coefficient studies in linseed. Journal of Biological Sciences 1(6): 446-447.

Mündel HH, Blackshaw RE, Byers JR, Huang HC, Johnson DL, Keon R, Kubik J, McKenzie R, Otto B, Roth B \& Stanford K (2004) Safflower Production in the Canadian Prairies. Agriculture and Agri-Food Canada, Lethbridge Research Centre, Lethbridge.

Murphy D (1999) The future of new and genetically modified oil crops. In: Janick J (ed) Perspectives on new crops and new uses. ASHS Press, Alexandria, Virginia, pp. 216-219.

Nimbkar N (2002) Safflower rediscovered. Times Agricultural Journal 2: 32-36.

Omidi AH, Ghannadha MR, Ahmadi MR \& Peighambari SA (1999) Study of agronomic traits of spring Safflower through multivariate statistical methods. Iranian Journal of Agricultural Sciences 30: 817-826.

Omidi AH, Khazaei H \& Hongbo SH (2009) Variation for Some Important Agronomic Traits in 100 Spring Safflower (Charthamus tinctorius L.) Genotypes. American-Eurasian Journal of Agriculture and Environmental Science 5(6): 791-795.

Öztürk E, Özer H \& Polat T (2008) Growth and yield of Safflower genotypes grown underirrigated and nonirrigated conditions in a highland environment Department of Field Crops, Faculty of Agriculture, Atatürk University, Erzurum, Turkey. Plant, Soil and Environment 54(10): 453-460.

Padulosi S, Eyzaquirre, P \& Hodgkin T (1999) Challenges and strategies in promoting conservation and use of neglected and underutilized crop species. In: Janick J (ed) Perspectives on new crops and new uses. ASHS Press, Alexandria, Virginia, pp. 140-145.

Roopa VK \& Ravikumar RL (2008) Character association studies on cultivars of Safflower (Carthamus tinctorius L.). Karnataka Journal of Agricultural Sciences 21(3): 436-437.

Samarajeewa P, Nilanthi R \& Liyange A (2004) Morphological and molecular characterization of locally collected wild rice germplasm. Annals of the Sri Lanka Department of Agriculture 6: 177-186.

Seetharam K, Thirumeni S \& Paramasivam K (2004) Estimation of genetic diversity in rice (Oryza sativa L.) genotypes using SSR markers and morphological characters. African Journal of Biotechnology 8(10): 20502059.

Singh V, Deshpande MB, Nimbkar N \& Singh RJ (2007) The first non-spiny Genetic resources, chromosome engineering and crop improvement. CRC Press, Boca Raton, USA. Safflower released in India. Sesame and Safflower Newsletter 18: 77-79.

Thies E (2000) Promising and Underutilized Species Crops and Breeds. Eschborn, Germany: GTZ.

Vavilov NI (1951) The origin, variation, immunity and breeding of cultivated plants. Chronica Botanica 13: 136.

Wachsmann N, Jochinke D, Potter T \& Norton R (2008) Growing Safflower in Australia: Agronomic research and suggestions to increase production levels. Proceedings of the VII International Safflower Conference, Wagga Wagga, New South Wales Australia. Available from: http://www.australian oilseeds.com/ (Accessed: 23 Jun. 2014).

Weiss EA (1971) Castor, Sesame and Safflower. Barnes and Noble, Inc., New York.

Weiss EA (1983) Safflower. In: Oilseed crops. Tropical agriculture series. Longman, London, pp. $216-281$.

Weiss EA (2000) Oil Seed Crops. Blackwell Science Ltd., Oxford, UK. 